Унусян Ульяна Вячеславовна

аспирант кафедры социологии

Российского университета дружбы народов
Unusyan Ulyana Vyacheslavovna

PhD student, Social Science Department, Peoples' Friendship University of Russia

\section{АСПЕКТЫ ВЗАИМОДЕЙСТВИЯ ОРГАНОВ МЕСТНОГО САМОУПРАВЛЕНИЯ И ОБРАЗОВАТЕЛЬНЫХ УЧРЕЖДЕНИЙ НА ПРИМЕРЕ ГОРОДА ОДИНЦОВО МОСКОВСКОЙ ОБЛАСТИ}

\begin{abstract}
Аннотация:
В статье рассмотрены особенности получения дошкольного и школьного образования, определены проблемы, возникающие в данной сфере. Основное внимание уделено процессу взаимодействия органов местного самоуправления с дошкольными образовательными учреждениями. Обозначены задачи органов местного самоуправления города Одинцово Московской области в сфере осуществления взачмодействия со школами и дошкольными образовательными учреждениями города.
\end{abstract}

Ключевые слова:

школьное образование, дошкольное образование, образовательное учреждение, орган местного самоуправления, модернизация дошкольного образования.

\section{ASPECTS OF INTERACTION BETWEEN LOCAL GOVERNMENT AUTHORITIES AND EDUCATIONAL INSTITUTIONS BY CASE STUDY OF THE CITY OF ODINTSOVO OF MOSCOW REGION}

Summary:

The article examines the features of getting preschool and school education and defines the problems arising in this sphere. The key attention is paid to the process of interaction between local government authorities and preschool educational institutions. The paper identifies the tasks of local government authorities of the city of Odintsovo of Moscow Region in the field of interaction with schools and preschool educational institutions of the city.

Keywords: school education, preschool education, educational institution, local government authority, modernization of preschool education.

Ключевым фрактором конкурентоспособности инновационной экономики является человеческий капитал. Под ним понимают совокупность навыков, умений, знаний, которые используются с целью удовлетворения потребностей человека и социума. Образование вносит существенный вклад в данный капитал. Однако, оценивая потенциал современной российской системы образования, делаем вывод, что ее функции не могут быть реализованы в полной мере.

Актуальность настоящего исследования обусловлена тем фактом, что образовательные учреждения являются наиболее эфффективным средством подготовки как будущих специалистов - сотрудников местных органов власти, так и обычных членов общества, которые будут пользоваться услугами местных органов власти. Кроме того, образовательные учреждения способны обеспечивать прозрачность деятельности органов местного самоуправления.

Научная новизна статьи заключается в анализе взаимодействия органов местного самоуправления с образовательными учреждениями на примере города Одинцово Московской области. На основании результатов исследования сделаны теоретические выводы о влиянии взаимодействия образовательных учреждений с органами местного самоуправления на создание имиджа и развитие муниципального образования.

Анализ показателей эффективности образовательных учреждений в городе Одинцово выглядит следующим образом: в 2017 г. для педагогов предусмотрено повышение заработной платы на 58 \%, 2018 - 75, 2019 - 80 и к 2020 г. на 100 \% Самая высокая наполняемость наблюдается в лицее № 2 и составляет около 27,9 человека. Количество обучающихся на 1 педагога 17 учеников. Средняя нагрузка на каждого преподавателя - 21,6 человека, или 1,2 ставки. Максимальная нагрузка на каждого преподавателя составляет 1,48 ставки.

Приведенные данные были получены с использованием методов анализа, таких как наблюдение, измерение и сравнение. С помощью наблюдения было составлено общее представление о возникшем вопросе, через измерение были получены статистические данные, а метод сравнения позволил дать окончательную характеристику и подвести итоги.

Объектом исследования выступили образовательные учреждения города Одинцово, предметом - управленческие отношения, возникающие при взаимодействии органов муниципальной власти с местными образовательными учреждениями.

Цель статьи - охарактеризовать особенности взаимодействия органов муниципальной власти с местными образовательными учреждениями. 
Автором была выдвинута гипотеза о положительном влиянии эффрективного взаимодействия органов муниципальной власти с местными образовательными учреждениями на имидж и последующее развитие муниципального образования.

Существует прямая взаимосвязь между органами самоуправления и образовательными учреждениями, которая заключается в нижеперечисленном:

- бесплатное образование по общеобразовательным программам;

- предоставление дополнительного или дошкольного образования;

- содержание в надлежащем виде зданий и сооружений общеобразовательных учреждений.

Реализуя полномочия в сфере образования, органы местного самоуправления муниципальных районов и городских округов прежде всего организуют деятельность муниципальных образовательных учреждений и осуществляют в соответствии с законодательством контроль за деятельностью всех организаций, которые участвуют в образовательном процессе либо создают необходимые для этого условия (ремонт школьных зданий, питание школьников и др.).

Образовательные учреждения как юридические лица имеют широкие права в осуществлении образовательного процесса. Это касается как выбора содержания образования, так и хозяйственной самостоятельности.

Российская система дошкольного образования в настоящий момент переживает сложный период, подвергается постоянным изменениям. Так, в 2010 г. в практику работы дошкольных образовательных учреждений (ДОУ) введены федеральные государственные требования [1], в 2013 г. вступил в силу новый Федеральный закон «Об образовании в РФ» [2], в 2014 г. введен Федеральный государственный образовательный стандарт ДОУ [3].

До 2010 г. дошкольная педагогическая практика основывалась на работах К.Л. Печоры, М.Д. Ковригиной, Н.М. Аксариной и др. Теперь данная практика трансформируется, и изменения несут в себе некоторые риски. Такие фракторы, как переход ДОУ в автономный режим и нехватка финансирования, недостатки законодательной базы, дестабилизируют работу специалистов в рассматриваемой сфере и нарушают функционирование системы в целом.

Для устранения указанных проблем принимаются следующие меры:

- разработка локальных актов, сопровождающихся федеральными нормативными документами;

- осуществление в регионах просветительской работы по приоритетным вопросам организации педагогической деятельности;

- создание рабочих групп, ориентированных на решение имеющихся педагогических задач.

В Москве на сегодняшний день в силу закона № 131-Ф3 «Об общих принципах организации местного самоуправления в РФ» по факту закреплена двойственность территориального и муниципального деления и определены полномочия органов местного самоуправления [4]. Таким образом, на одной территории одновременно действуют муниципальная и государственная исполнительная власть.

В деятельности органов города Одинцово не затронуты вопросы:

1) создания, реорганизации, ликвидации, лицензирования образовательных учреждений;

2) установления местных налогов и сборов на цели образования;

3) содержания санитарных норм, норм охраны здоровья воспитанников, учащихся, оснащенности учебного процесса и оборудования учебных помещений;

4) установления дополнительных к федеральным льгот для учащихся, воспитанников, педагогических работников образовательных учреждений, а также видов и норм материального обеспечения для вышеназванных.

В 2015 г. из областного бюджета на эти цели выделено более 38 млн р.

За два года план программы по увеличению количества дошкольных учреждений выполнен на $48 \%$ - уже создано 13238 мест.

Есть изменения и в содержании образовательного процесса в дошкольных организациях. Впервые приняты государственные образовательные стандарты дошкольного образования. Они будут внедряться поэтапно до 1 января 2018 г. В 2016 г. в регионе были определены 16 пилотных детских садов по внедрению стандартов.

Образование относят к ведению местной администрации лишь в части дополнительного образования, однако многие учреждения в данной сфере являются частными и, соответственно, муниципальным органам не подчиняются. Что касается ДОУ, на органы местного самоуправления возлагается ответственность только за их материальное обеспечение, тогда как непосредственно образовательный процесс контролируется и регламентируется государством [5, с. 68].

Таким образом, возможности органов местного самоуправления в социальной сфере ограниченны. Деятельность органов местного управления существует в определенной среде, которая имеет свои особенности. К ним относят: внутреннюю государственную политику, которая требует ускорения процесса принятия и развития решений; непрерывные реформирование и изменения; 
необходимость усиливать контакты с населением и бизнесом; необходимость жесткой нормативной регламентации административной деятельности.

Отметим, что на современном этапе в условиях активно развивающегося социума образование выступает в роли процесса получения основной информации. Кроме того, образование является механизмом взаимодействия социальных субъектов, а информация - содержательной стороной взаимодействия социальных субъектов.

Чтобы основательно автоматизировать взаимодействие ДОУ с органами местной власти, необходимо принятие следующих мер:

1) проведение исследований в области организации местной власти, которые ориентированы на определенные практические вопросы;

2) создание новых информационных ресурсов и открытие удаленного доступа органам местной власти к существующим электронным базам данных;

3) разработка алгоритма принятия решений по типовым вопросам [6, с. 84].

В настоящее время к ключевым задачам органов местного самоуправления города Одинцово относятся развитие системы образования и создание условий обеспечения дошкольников услугами в области воспитания, образования, ухода и присмотра.

Поддержка негосударственного сектора системы дошкольного образования должна являться одним из главных направлений муниципальной политики. Проблемы, которые возникают при открытии частного ДОУ с функциями ухода и присмотра, снижают потенциал участия в достижении нужного муниципальному образованию результата.

В рассматриваемой сфере целесообразно:

1) создание рабочей группы по поддержке негосударственных форм образования дошкольников при комиссии по здравоохранению, образованию и социальной поддержке;

2) включение в план работы на 2017 г. мероприятий, которые направлены на взаимодействие органов местного самоуправления и негосударственных дошкольных организаций города Одинцово.

Основными вопросами в области образования в городе Одинцово Московской области являются:

- повышение качества образовательных услуг;

- усиление мотивации педагогов с целью увеличения показателей качества образовательного процесса;

- приведение численности учащихся в одном классе в соответствие с нормативами.

Подведем итоги, касающиеся города Одинцово:

1. За прошедший 2016 год некоторые показатели стали очень близки к нормативным, например наполняемость классов, фонд оплаты труда. Положительная динамика прослеживается и в численности педагогов.

2. Некоторым школам требуется выравнивание субвенций, поэтому целесообразно проведение мероприятий по оптимизации расходов образовательных учреждений.

Таким образом, исходя из развития современного социума, постоянного роста его запросов и требований к органам власти, сегодня просто не существует однозначного разрешения проблем, которые связаны с перечисленными выше фракторами, как в городе Одинцово, так и во всей стране. Для полного их устранения требуется комплексный подход совместно с четкой стратегией развития образовательных учреждений.

\section{Ссылки:}

1. Об утверждении и введении в действие федеральных государственных требований к структуре основной общеобразовательной программы дошкольного образования : приказ Министерства образования и науки РФ от 23 нояб. 2009 г. № 655.

2. Об образовании в РФ : федер. закон от 29 дек. 2012 г. № 273-Ф3 : ред. от 3 июля 2016 г.

3. Об утверждении Федерального государственного образовательного стандарта дошкольного образования : приказ Министерства образования и науки РФ от 17 окт. 2013 г. № 1155.

4. Об общих принципах организации местного самоуправления в РФ : федер. закон от 6 окт. 2003 г. № 131-Ф3 : ред. от 29 дек. 2016 г.

5. Устав Одинцовского муниципального района МО : утв. решением Совета депутатов Одинцовского района МО от 24 июня 2005 г. № $1 / 47$ : ред. от 13 марта 2015 г.

6. Зерчанинова Т.Е. Исследование социально-экономических и политических процессов. М., 2013. 270 с.

\section{References:}

Zerchaninova, TE 2013, Research of social and economic and political processes, Moscow, 270 p., (in Russian). 